\title{
Reasons for Elective Cesarean Section among Pregnant Women in Ranya District
}

\author{
Khalat K.Fares $^{1}$, Renas M.khzr², Sanna H.abdulsahib ${ }^{2}$ \\ 1Community Health department, Koya Technical Institute, Erbil Polytechnic University, Erbil, 44001, Iraq \\ khalat.k.fares@gmail.com \\ 2 Collage of Nursing/ Raparin University. \\ Corresponding Author: Khalat K.Fares, khalat.k.fares@gmail.com
}

\begin{abstract}
Background: Caesarean Section rates are progressively increasing in most parts of the world. It is an important role can improve infant and or maternal outcomes. However, when used inappropriately the potential harm may exceed the potential benefit of caesarean section.

Objective: This study was conducted to determine socio - demographic characteristics of the study sample, to determine reasons associated with selection of elective caesarean section and to find out the relationship between reasons of cesarean section and some socio-demographic characteristics.
\end{abstract}

Methods: This cross-sectional study was conducted from Dec17th 2017 to April $25^{\text {th }} 2018$ in Ranya District, Kurdistan region. A quantitative design descriptive study was conducted on 64 women delivered abdominally at maternal and child Hospital and from outpatient clinics In Ranya District. Data regarding sociodemographic characters and reasons to conduct elective caesarean section was collected in a special designed questionnaire.

Results: There was significant difference between Family incomes with regard to the reasons for elective caesarean section. The study found that a majority of the women surveyed $81.2 \%$ verbalized understanding that caesarean section was dangerous and is critical medical decision and situation despite this the fear and pain of normal delivery and vaginal dilatation in future had more impact on their decision to have a caesarean section with $85.9 \%$ of the women surveyed.

Conclusion: Fear and pain of normal delivery is the main reason behind many women's preference for elective caesarean section in addition societal reasons such as inequality of care has changed the concept of good and normal birthing. Reduction of elective caesarean section cannot be achieved without regulating caesarean section use for primiparous in the Private Hospitals.

Keyword: Elective caesarean section, Pregnant women, Private Hospital

\section{INTRODUCTION}

Cesarean section is one of the frequently performed surgical procedures in obstetrics. It is a birth of the fetus through an abdominal and uterine incision ${ }^{1}$. The rate of elective caesarean section (CS) delivery has increased over the past 30 years, due to several factors including 


\section{Proceeding of the $2^{\text {nd }}$ Scientific Conference on Women's Health \\ 2-3 September 2020 - Hawler Medical University}

changes in the management of breech presentation, previous CS, maternal medical illness, Fetal diseases, and CS on 'maternal request ${ }^{2}$.

According to World health organization, the acceptable rate of cesarean section delivery is $15 \%$ of all birth in developed countries. However, the rate has been increasing worldwide ${ }^{3}$.

In the United Kingdom in 1953, only $2 \%$ of all recorded deliveries were cesarean deliveries but the rate continues to increase reached $21 \%$ in $2001^{4}$. In developing countries like Iran, the rate rose from $35 \%$ in 2000 to $47 \%$ in $2005^{5}$.

The global concern around CS rates is understandable. When medically justified, a CS can prevent maternal and perinatal mortality and morbidity. There is no evidence, however, showing the benefits of the procedure for women or infants where it is not required. CS is associated with short- and long-term risk, which can extend beyond the current delivery and affect future pregnancies. In addition, the increase in CS rates seems uncontrollable, with no signs that it is slowing down ${ }^{6}$.

Increasing rates of caesarean sections are a continuing concern for the obstetric and public health communities. Fears of maternal and neonatal morbidity from vaginal delivery may be encouraging this trend ${ }^{7}$. In addition, Legally and ethically, women have the right to choose their management; however, caesarean section is not without morbidity and mortality. Hence, these factors need to be considered when discussing elective caesarean section as an option for childbirth ${ }^{7}$.

Women's requests for CS may be an important determinant of birth outcome, particularly in countries with growing privatisation and options for patient choice. Most research focuses on women's fears of the physiological consequences of vaginal delivery and their desire to keep their sexual performance intact. For this reason, the debate has focused on providing consumers with knowledge on the risks associated with vaginal and operative deliveries so that decisions about birth may be rationally informed ${ }^{8}$.

The requesting CS without medical indications increasing for a variety of reasons. But the most common concerns are pain, fear, long duration, stress and exhaustion and Fetal distress that might arise in a vaginal birth ${ }^{9}$. Women may experience a variety of fears in associated with pregnancy and child birth. The purpose of this study to describe the object, cause, to identify the factors associated with requesting caesarean section.

\section{METHODS}

A quantitative design descriptive study was conducted on Dec17th 2017 to April $25^{\text {th }} 2018$ in Maternal and child Hospital and outpatient clinic in Ranya District. Non- probability purposive sample was used to target (64) pregnant women prefer cesarean section the data were collected through the interviewing technique face to face approach was used. Data were presented using descriptive statistics in the form of frequencies, percentage and Chi square test. 
Ethical considerations: Written official permissions have been obtained from the College of Nursing University of Raparin, the Ministry of Health (Maternal and Child Health Centre) and prior to the initiation of the study.

\section{RESULTS}

Of the total sample (64) pregnant women were Participate in this study from (18-39) years old. Mean of age were (28.7), most of them level of education were primary school $(28.1 \%)$. Unemployed of women were $(93.8 \%)$, about (39.1\%) were primiparous. The majority of them (65.6\%) they choice Private Hospital to deliver a baby. As illustrated in Table (1).

Table (2) concentrated that $(85.9 \%)$ of women the reason of selective caesarean section were fear and pain of normal vaginal delivery also fear of further cosmetic genital organ surgery in the future. Majority of them $(81.2 \%)$ believe that Caesarean section is dangerous and it is critical situation, despite that only $(26.5 \%)$ of women think that post maturity affects the decision of caesarean section. There was significant correlation between Family income and reasons of Elective Cesarean Section $\mathrm{P}$ value is (0.04), Women think that Family income affects your Decision to choose Caesarean Section.

Women with sufficient income believes that inequality of care was the reason of caesarean section it was $46.9 \%$, while the rate were lower between low- and middle-income class women it was $15.6 \%, 4.7 \%$ respectively. 


\section{Proceeding of the $2^{\text {nd }}$ Scientific Conference on Women's Health 2-3 September 2020 - Hawler Medical University}

Table 1: Distribution of the sample according to socio-demographic characteristics

\begin{tabular}{|c|c|c|}
\hline Age group & Frequency & Percentage \\
\hline $18-23$ & 8 & 12.5 \\
\hline $24-29$ & 30 & 46.9 \\
\hline $30-39$ & 26 & 40.6 \\
\hline Total & 64 & 100 \\
\hline Level of education & Frequency & Percentage \\
\hline Illiterate & 10 & 15.6 \\
\hline Able to reading and writing & 9 & 14.1 \\
\hline Primary school graduate & 18 & 28.1 \\
\hline Secondary school graduate & 13 & 20.3 \\
\hline Institute graduate & 9 & 14.1 \\
\hline College and post graduate & 5 & 7.8 \\
\hline Total & 64 & 100 \\
\hline Occupation status & Frequency & Percentage \\
\hline Governmental employed & 3 & 4.7 \\
\hline Self employed & 1 & 1.6 \\
\hline Unemployed & 60 & 93.8 \\
\hline Total & 64 & 100 \\
\hline Family income & Frequency & Percentage \\
\hline Insufficient & 15 & 23.4 \\
\hline Barely sufficient & 17 & 26.6 \\
\hline Sufficient & 32 & 50.0 \\
\hline Total & 64 & 100 \\
\hline Gravida & Frequency & Percentage \\
\hline $1-2$ & 37 & 57.8 \\
\hline $3-4$ & 20 & 31.3 \\
\hline $5-6$ & 4 & 6.3 \\
\hline $7-9$ & 3 & 4.7 \\
\hline Total & 64 & 100 \\
\hline Para & Frequency & Percentage \\
\hline $1-2$ & 44 & 68.8 \\
\hline $3-4$ & 16 & 25.0 \\
\hline $5-6$ & 4 & 6.3 \\
\hline Total & 64 & 100 \\
\hline $\begin{array}{l}\text { No. of children delivered by } \\
\text { C/S }\end{array}$ & Frequency & Percentage \\
\hline 0 or Primiparous & 25 & 39.1 \\
\hline $1-2$ & 20 & 31.3 \\
\hline $3-4$ & 11 & 17.2 \\
\hline 5 & 8 & 12.5 \\
\hline Total & 64 & 100 \\
\hline Type of Hospital & Frequency & Percentage \\
\hline Governmental Hospital & 22 & 34.4 \\
\hline Private Hospital & 42 & 65.6 \\
\hline Total & 64 & 100 \\
\hline
\end{tabular}


Proceeding of the $2^{\text {nd }}$ Scientific Conference on Women's Health

2-3 September 2020 - Hawler Medical University

Table 2: Reasons behind preference of Cesarean Section among Pregnant women

\begin{tabular}{|lcccr|}
\hline Reasons & Yes & $\%$ & No & \% \\
\hline $\begin{array}{l}\text { Do you know that cesarean section is dangerous and it is critical } \\
\text { situation }\end{array}$ & 52 & 81.25 & 12 & 18.75 \\
\hline Have you doctors told you that you must do cesarean section & 34 & 53.12 & 30 & 46.88 \\
\hline $\begin{array}{l}\text { Are you fear and pain of normal delivery the main causes of } \\
\text { cesarean section }\end{array}$ & 55 & 85.94 & 9 & 14.06 \\
\hline $\begin{array}{l}\text { Do you think that family income affects your decision to choose } \\
\text { cesarean section }\end{array}$ & 45 & 70.31 & 19 & 29.69 \\
\hline $\begin{array}{l}\text { Do you have information that narrow pelvic bone will cause } \\
\text { cesarean section }\end{array}$ & 39 & 60.94 & 25 & 39.06 \\
\hline Health Care Quality & 41 & 64.06 & 23 & 35.94 \\
\hline Do you know that abnormal fetal position causes cesarean section & 28 & 43.75 & 36 & 56.25 \\
\hline Inequality of Care & 50 & 78.12 & 14 & 21.88 \\
\hline $\begin{array}{l}\text { Will cosmetic of Genital organ or Vaginal dilatation in future } \\
\text { influence of your Decision }\end{array}$ & 55 & 85.94 & 9 & 14.06 \\
\hline $\begin{array}{l}\text { Was post maturity cause of making decision to do cesarean } \\
\text { section }\end{array}$ & 17 & 26.56 & 47 & 73.44 \\
\hline
\end{tabular}




\section{Proceeding of the $2^{\text {nd }}$ Scientific Conference on Women's Health}

2-3 September 2020 - Hawler Medical University

Table (3): Relationship between Family income and Reasons of Elective Cesarean Section

\begin{tabular}{|c|c|c|c|c|c|c|c|c|c|c|c|c|c|}
\hline \multicolumn{14}{|c|}{ Family income } \\
\hline \multirow{2}{*}{ Reasons } & \multicolumn{4}{|c|}{ Insufficient } & \multicolumn{4}{|c|}{ Barley sufficient } & \multicolumn{4}{|c|}{ Sufficient } & \multirow{2}{*}{$p$ value } \\
\hline & Yes & & No & & Yes & & No & & Yes & & No & & \\
\hline $\begin{array}{l}\text { Do you know that cesarean section is dangerous and it is critical } \\
\text { situation }\end{array}$ & 10 & $(15.6 \%)$ & 5 & $(7.8 \%)$ & 12 & $(18.7 \%)$ & 5 & $(7.8 \%)$ & 20 & $(31.3 \%)$ & 12 & $(18.8 \%)$ & 0.847 \\
\hline Have you doctors or nurse told you that you must do cesarean section & 5 & $(7.8 \%)$ & 10 & $(15.6 \%)$ & 10 & $(15.6 \%)$ & 7 & $(10.9 \%)$ & 10 & $(15.6 \%)$ & 22 & (34.4\%) & 0.148 \\
\hline $\begin{array}{l}\text { Are you fear and pain of normal delivery the main causes of cesarean } \\
\text { section }\end{array}$ & 7 & $(10.9 \%)$ & 8 & $(12.5 \%)$ & 10 & $(15.6 \%)$ & 7 & $(10.9 \%)$ & 30 & $(46.9 \%)$ & 2 & $(3.1 \%)$ & 0.0009 \\
\hline $\begin{array}{l}\text { Do you think that family income affects your decision to choose } \\
\text { cesarean section }\end{array}$ & 10 & $(15.6 \%)$ & 5 & $(7.8 \%)$ & 5 & $(7.8 \%)$ & 12 & $(18.8 \%)$ & 10 & $(15.6 \%)$ & 22 & $(34.4 \%)$ & 0.0431 \\
\hline $\begin{array}{l}\text { Do you have information that narrow pelvic bone will cause cesarean } \\
\text { section }\end{array}$ & 14 & $(21.9 \%)$ & 1 & $(1.6 \%)$ & 7 & $(10.9 \%)$ & 10 & $(15.6 \%)$ & 10 & $(15.6 \%)$ & 22 & $(34.4 \%)$ & 0.0003 \\
\hline Health care Quality & 5 & $(7.8 \%)$ & 10 & $(15.6 \%)$ & 10 & $(15.6 \%)$ & 7 & $(10.9 \%)$ & 10 & $(15.6 \%)$ & 22 & $(34.4 \%)$ & 0.148 \\
\hline Do you know that abnormal Fetal position causes cesarean section & 2 & $(3.1 \%)$ & 13 & $(20.3 \%)$ & 15 & $(23.4 \%)$ & 2 & $(3.1 \%)$ & 25 & $(39.1 \%)$ & 7 & $(10.9 \%)$ & 0.0001 \\
\hline Inequality of Care & 10 & (15.6\%) & 5 & $(7.8 \%)$ & 3 & $(4.7 \%)$ & 14 & (21.9\%) & 30 & (46.9) & 2 & (3.1\%) & 0.0001 \\
\hline $\begin{array}{l}\text { Will cosmetic of Genital organ or Vaginal dilatation in future } \\
\text { influence of your Decision }\end{array}$ & 14 & $(21.9 \%)$ & 1 & $(1.6 \%)$ & 7 & $(10.9 \%)$ & 10 & $(15.6 \%)$ & 15 & $(23.4 \%)$ & 17 & $(26.6 \%)$ & 0.0039 \\
\hline Was post maturity cause of making decision to do cesarean section & 3 & $(4.7 \%)$ & 12 & $(18.8 \%)$ & 4 & $(6.3 \%)$ & 13 & $(20.3 \%)$ & 20 & $(31.3 \%)$ & 12 & $(18.8 \%)$ & 0.0044 \\
\hline
\end{tabular}




\section{Proceeding of the $2^{\text {nd }}$ Scientific Conference on Women's Health 2-3 September 2020 - Hawler Medical University}

\section{DISCUSSION}

This study aimed to identify factors behind the preference of cesarean section. The rates of maternal choice of or preference for cesarean section remain unclear duo to personal and societal factors.

Fear of pain in normal delivery were the main causes of elective cesarean section it was $85.9 \%$ as illustrated in the table 2. Karlstoyem et al showed that one-third cesarean sections were optional. Fear and anxiety about child's health and previous history of elective cesarean section ${ }^{10}$. Also, Saisto reported that parturition fear has lead to $8 \%$ to $22 \%$ increase in elective cesarean section in a very limited number of women ${ }^{11}$. In the other study Johanson revealed that pregnant women preferred elective cesarean section because it is comfort in comparison with vaginal delivery ${ }^{12}$. The main categories of fear due to not having knowledge, unpleasant experience of others.

In the other study Sharifi et al in 2007revealed that due to advancement in surgical procedure in the past decades, elective cesarean section has increasingly become popular and critical issue for maternity practitioners, Hospitals as well as maternity client ${ }^{13}$.

Half of elective cesarean section were more common among sufficient family income and primiparous women' the study conducted by Fernando in 2002 were support our findings wealthy women prefer cesarean section those with more antenatal attendance, primiparous women with lower gestational risk. Overall, $83 \%$ of women who had had cesarean section had a repeated procedure ${ }^{14}$.

Private Hospital play a role in increasing elective cesarean section the rate of private Hospital is nearly twice that of Public Hospitals as illustrated in Table (1). Because Government run Hospitals do not allow elective cesarean section without medical indications. Cesarean section itself not only factors and improves obstetric complications, but also it may place more financial task on Family and Government.

The majority of pregnant women were $81.2 \%$ verbalized understanding that cesarean section was dangerous and it is critical situation, the reason behind preference it may be due to fear not having knowledge in normal birth and inappropriate communication of health care staff and inequality were the reasons. Moscariello and Bolk, 2011 they revealed that one major reason for rising cesarean section rate is the increased perception among women of these operation as safe, despite the associated adverse outcomes ${ }^{15}$. 


\section{Proceeding of the $2^{\text {nd }}$ Scientific Conference on Women's Health 2-3 September 2020 - Hawler Medical University}

Data analysis showed that maternal age rising at the time of first delivery the average age was (28.7\%) years $40 \%$ of women were age (30-39) years old and approximately Half of them were primiparous. Maternal age at delivery has increased during recent Decades, as has the rate of cesarean section 16 .

Similar to the study in Norway in 2016 the average age at first child birth was 28.7years and $20 \%$ of women were 35 years or older at delivery and cesarean section rate was $16.5 \%{ }^{17}$.

\section{CONCLUSIONS}

The rate of elective cesarean section increase in the developed and developing Countries as well as Ranya District in Kurdistan Region, despite that the actual number of maternal requesting cesarean section in the absence of clear indications for themselves or their baby's outcome is unknown. The private Hospital has a negative role in increasing elective cesarean sections, A significant reduction in the overall rate cannot be achieved without regulating cesarean section use for primiparous in the Private hospitals.

\section{References}

1. Schindle, M. Briner, p. Reingraber,M: elective cesarean section Vs spontaneous delivery a comparative study of birth experience. Acta Obestet Gynecol Scand, 2003. 82(9), 834-40.

2. Kolas T, Hofoss D, Daltveit AK, Nilsen ST, Henriksen T, Hager R, et al: Indications for caesarean deliveries in Norway. Am J Obstet Gynecol. 2003;188:86470.

3. Gibbons L, Belizán JM, Lauer JA, Betrán AP, Merialdi M, Althabe F. The global numbers and costs of additionally needed and unnecessary caesarean sections performed per year: overuse as a barrier to universal coverage. World health report. 2010 Jan 1;30(1):1-31.

4. Lavender, I. Hofmyer, GJ. Neslon, JP. Kingdon, C. Gyte, D: cesarean section for not medical reason at Term.Cochrance Database Syst Rve, 2006. 3CD004660.

5. Ahmad-Nias, S. Delevar, B. Eini-Zinab, H. Mehryar, A, 2009: cesarean section in the Islamic republic in Iran prevalence and some socio demographic correlates. East Mediterr Health J, 1389-1398.

6. Fioretti B, Reiter M, Betran A, Torloni M. Googling caesarean section: a survey on the quality of the information available on the Internet. BJOG 2015;122:731-9.

7. Betran A, Merialdi M, Lauer J, Bing-Shun W, Thomas J, Van Look P, et al. Rates of caesarean section: analysis of global, regional and national estimates. Paediatr Perinat Epidemiol 2007;21:98-113.

8. De Mello e Souza C.C-sections as ideal births: The cultural construction of beneficience and patients' rights in Brazil.Cambridge Q Healthcare Ethics 1994; 3:358366. 


\section{Proceeding of the $2^{\text {nd }}$ Scientific Conference on Women's Health 2-3 September 2020 - Hawler Medical University}

9. Guihard, P. Blonder, B 2001: trends and risk factors of cesarean sections in France between 1981-1995, Leassons for reducing the rates in the future BJOG.

10. Karlistrom, A. Radistal,I. Erikson, C. Rubertsson, C: cesarean section without medical reasons , 1997-2006 A Swedish rigiester study Birth, 2010:37(1): 11-20PubMed.

11. Siasto, T. Kajaa, R.Yalikorkala, O. Halmismaki, E: reduce pain tolerance during and after pregnancy in women suffering from fear of labor pain 2001,93(2):123-7pubMed.

12. Johanson, RB. EL-Timi, S.Rigby, C. Yong, P. Jones, P: cesarean section by choice could fulfil the inverse care low. Eur J Obestet Gynecol Reprod Biol. 2001. 97(1), 202.

13. Sharifi Rad,GB. Fathian, Z. Tiran, M. Mohlek, B: study on behaviral intention model to the attitude of pregnant women toward normal delivery and cesarean section in Province of Esfahan, Khominy Shuhur, 1385 J llam Uni Med Sci, 2007;15(1):19-24 Persian.

14. Fernando, C. Behangue,D.Cesar, G. Victora, F: consumer Demand of cesarean section in Brazil population based birth cohort study linking Ethnographic and epidemiological method. BMJ 2002,324, 942-5.

15. Moscarello,M.Bolk, K: cesarean delivery and inductionof labor in Colorado : an analysis of Current Trend and Demographic. Denver. Corolando Department of Public Health and environment, 2011. Health watch81.

16. World Health Organisation. European Health for all Data base (HFA-DB) http://databaseeurowho.int/hfadb. Accessed NOvember2014. Medical health register in Norway Data base http:// Statstik.TH.no/mfr/accessed November, 2014.

17. Herstad, Lina, et al. "Elective cesarean section or not? Maternal age and risk of adverse outcomes at term: a population-based registry study of low-risk primiparous women." BMC pregnancy and childbirth 16.1 (2016): 230. 